\title{
Introduction to a Special Issue on Research with Youth Exposed to Disasters and Violence
}

\author{
Victor G. Carrión · Carl F. Weems
}

Published online: 15 June 2013

(C) Springer Science+Business Media New York 2013

This issue of the Child and Youth Care Forum presents six papers on research with youth exposed to disasters and violence. The International Work Group on Treatment Interventions for Children Exposed to War and Violence sponsored by the Stanford Early Life Stress Research Program (held at Stanford University's Freeman Spogli Institute for International Studies May 5-May 9, 2012) was the impetus for this special issue and highlighted that researchers have often learned a great deal from initial mistakes or from discovering unforeseen paths leading to success. The purpose of this special issue is to bring together a set of papers that explore some of these methodological issues and the limitations inherent in this work and thereby advance the next generation of research across multiple levels of analysis. Clinicians and trauma researchers share the goal of increasing resilience and positive outcomes in individuals exposed to disaster or violence and so papers in the issue also have as a special focus how different research groups have approached the study of child trauma in terms of the development and application of interventions and identification of intervention targets.

The papers in this issue address "methods" in the broadest sense of the word from the approaches taken to implement regional prevention efforts, to novel school based methods of intervention delivery, to person centered statistical analyses of symptom trajectories following exposure to a disaster. The papers can be viewed as representing and analysis of both risk and resilience building by understanding the child at different levels of an ecological perspective to disasters and violence (e.g., Weems and Overstreet 2008). An ecological perspective emphasizes that families, peers, teachers, schools, neighborhoods, as well as broader communities are all integrally involved and represent potential circles of support for the individual child. Successful integration across levels of analysis allows for the identification of leadership tasks, sources of support, and effective utilization of

\footnotetext{
V. G. Carrión $(\bowtie)$

Stanford University School of Medicine, Stanford, CA, USA

e-mail: vcarrion@stanford.edu

C. F. Weems

Department of Psychology, University of New Orleans, New Orleans, LA 70148, USA

e-mail: cweems@uno.edu
} 
resources without duplication. At one of the broadest levels of analysis, Hamiel et al. (2013, this issue) introduce the concept of community resilience and the role of preparedness. In their article they present the Cohen-Harris Model of Urban Resilience as an example of an approach that can be taken to strengthen the circles of support that surround the child. Again at a very broad level, Song and Shaheen (2013, this issue) commentary highlights issues in conducting research on trauma in countries with very limited resources and research infrastructure. Their paper confronts the question of "can research typically conducted in economically advanced countries be applied/conducted in low and middle income countries?" In the article the authors emphasize the potential role of the World Health Organization.

The challenges inherent in conducting research in diverse cultures compounds the complexity that already exists in any type of trauma work in terms of the examination of children who have different levels of exposure, different types of trauma, and different resources. Pfefferbaum et al. (2013, this issue) provide a comprehensive review and comparative analysis of the methods used in published research on youth samples who experienced the events of September 11, 2001 (9/11); the 2004 Indian Ocean earthquake and tsunami; and Hurricane Katrina.

Within communities a critical source of support for children are their schools and teachers, yet many times school systems can be overtaxed by the many responsibilities imposed on them. Brief but effective interventions in times of trauma are needed. Baum et al. (2013, this issue) provide the results of a novel resilience-building intervention for teachers of children affected by war. Outcome results were highly promising and the delivery model provides an example of developing sustainable research intervention projects by facilitating competency among school staff. This competency remains after the research team leaves the collaboration.

At the center of the ecological approach is the child; there is a gap in our current understanding of what happens to children after disaster related trauma due to the relative scarcity of longitudinal studies (see Pfefferbaum et al. 2013, this issue). La Greca et al. (2013, this issue), utilize latent growth mixture modeling to reexamine data from a large cohort of children $(\mathrm{n}=568)$ assessed at 3-, 7- and 10-months after Hurricane Andrew. Three distinctive trajectories of response were identified, as well as the predictors of these trajectories. La Greca and colleagues paper highlights novel analytic techniques for war and disaster research and the data provide important information on potential intervention targets.

Finally, Kletter et al. (2013, this issue) outline the perspectives represented at the threeday International Work Group on Treatment Interventions for Children Exposed to War and Violence. A nine-phase model is presented to provide an overview of the perspectives for establishing partnerships between trauma teams and other organizations or schools to implement and disseminate treatment for this population of youth.

Acknowledgement We would like to thank Ms. Alison Geballe and Dr. Stephanie Evans for their support in making the International Work Group possible. We would also like to thank Dr Steven Berman for serving as action editor on our paper submission.

\section{References}

Baum, N. L., Cardozo, B. L., Pat-Horenczyk, R., Ziv, Y., Blanton, C., Reza, A., et al. (2013). Training teachers to build resilience in children in the aftermath of war: A cluster randomized trial. Child \& Youth Care Forum, doi:10.1007/s10566-013-9202-5. 
Hamiel, D., Wolmer, L., Spirman, S., \& Laor, N. (2013). Comprehensive child-oriented preventive resilience program in israel based on lessons learned from communities exposed to war, terrorism and disaster. Child \& Youth Care Forum,. doi:10.1007/s10566-013-9200-7.

Kletter, H., Rialon, R. A., Laor, N., Brom, D., Pat-Horenczyk, R., Shaheen, M., Hamiel., D., Chemtob, C., Weems, C. F., Feinstein, C., Lieberman, A., Reicherter, D., Song, S., \& Carrion, V.G. (2013). Helping children exposed to war and violence: Perspectives from an international work group on interventions for youth and families. Child \& Youth Care Forum, (doi: 10.1007/s10566-013-9203-4) (this issue).

La Greca, A. M., Lai, B. S., Llabre, M. M., Silverman, W. K., Vernberg, E. M., \& Prinstein, M. J. (2013). Children's postdisaster trajectories of pts symptoms: Predicting chronic distress. Child \& Youth Care Forum. doi: 10.1007/s10566-013-9206-1 (this issue).

Pfefferbaum, B. J., Weems, C. F., Scott, B. G. Nitiéma, P., Noffsinger, M. A., Pfefferbaum, R. L., Varma, V. \& Chakraburtty, A. (2013).Research methods in child disaster studies: A review of studies generated by the September 11, 2001, Terrorist Attacks; the 2004 Indian Ocean Tsunami; and Hurricane Katrina. Child \& Youth Care Forum. (this issue).

Song, S., \& Shaheen, M. (2013). Assessing the impact of violence and war on youth in low-and middleincome countries. Child \& Youth Care Forum,. doi:10.1007/s10566-013-9204-3.

Weems, C. F., \& Overstreet, S. (2008). Child and adolescent mental health research in the context of Hurricane Katrina: An ecological needs-based perspective and introduction to the special section. Journal of Clinical Child and Adolescent Psychology, 37, 487-494. 